\title{
Defect stabilization and reverse annealing in ZnO implanted with nitrogen at room and cryogenic temperature
}

Cite as: J. Appl. Phys. 123, 105701 (2018); https://doi.org/10.1063/1.5022152

Submitted: 11 January 2018 . Accepted: 22 February 2018. Published Online: 09 March 2018

Alexander Azarov (D), Elke Wendler, Edouard Monakhov, and Bengt G. Svensson

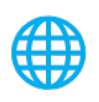

\section{ARTICLES YOU MAY BE INTERESTED IN}

A comprehensive review of $\mathrm{ZnO}$ materials and devices

Journal of Applied Physics 98, 041301 (2005); https://doi.org/10.1063/1.1992666

Extended defects in ZnO: Efficient sinks for point defects

Applied Physics Letters 110, 022103 (2017); https://doi.org/10.1063/1.4973463

Normal and reverse defect annealing in ion implanted II-VI oxide semiconductors

Journal of Applied Physics 122, 115701 (2017); https://doi.org/10.1063/1.4997847

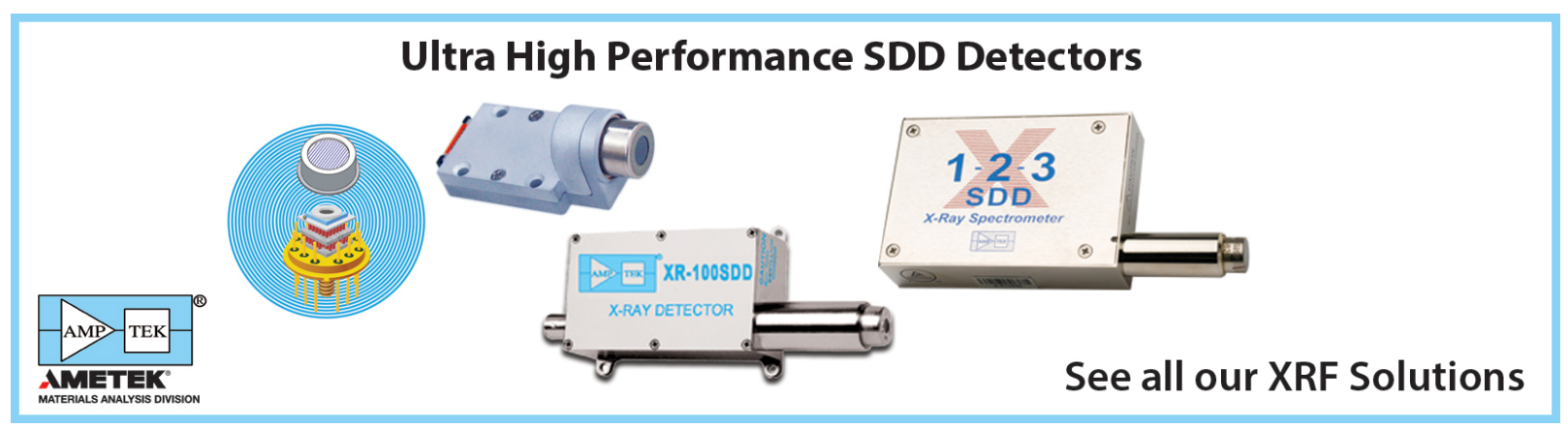




\title{
Defect stabilization and reverse annealing in $\mathrm{ZnO}$ implanted with nitrogen at room and cryogenic temperature
}

\author{
Alexander Azarov, ${ }^{1}$ Elke Wendler, ${ }^{2}$ Edouard Monakhov, ${ }^{1}$ and Bengt G. Svensson ${ }^{1}$ \\ ${ }^{1}$ Centre for Materials Science and Nanotechnology, Department of Physics, University of Oslo, \\ P.O. Box 1048 Blindern, N-0316 Oslo, Norway \\ ${ }^{2}$ Institut für Festkörperphysik, Friedrich-Schiller-Universität Jena, Max-Wien-Platz 1, 07743 Jena, Germany
}

(Received 11 January 2018; accepted 22 February 2018; published online 9 March 2018)

\begin{abstract}
Despite the fact that nitrogen is a potential acceptor dopant and one of the most studied elements in $\mathrm{ZnO}$, lacking understanding of associated defects and their thermal evolution limits realization of reliable p-type doping of $\mathrm{ZnO}$. Here, we use ion implantation to introduce $\mathrm{N}$ at room temperature (RT) and $15 \mathrm{~K}$ in $\mathrm{ZnO}$ samples with/without a pre-existing buried disorder layer formed by $\mathrm{Ag}$ ion bombardment aligned along the [0001] direction. The buried layer contains a high concentration of extended defects, which act as traps for migrating point defects. Channeling analysis shows that reverse annealing occurs in all the $\mathrm{N}$ implanted samples during post-implant heat treatment above $600^{\circ} \mathrm{C}$ with strong non-linear additive damage accumulation in the co-implanted samples. The reverse annealing effect is less stable in the RT co-implanted sample and the data suggest that a high local concentration of intrinsic point defects, like $\mathrm{Zn}$ interstitials, promotes the stability of the $\mathrm{N}$-defect clusters responsible for the reverse annealing. This suggestion is also corroborated by enhanced and defect-mediated $\mathrm{Ag}$ outdiffusion at $1100^{\circ} \mathrm{C}$ in the RT co-implanted samples. Published by AIP Publishing. https://doi.org/10.1063/1.5022152
\end{abstract}

\section{INTRODUCTION}

Point and extended defects as well as their complexes with dopants and residual impurities influence almost all physical properties of semiconductors. So, understanding the different types of defects and their interaction is crucial for mastering the properties of semiconductor materials and devices. This holds, in particular, for $\mathrm{ZnO}$, which is a wide band-gap semiconductor having potential for a variety of next generation solid-state devices in the fields of optoelectronics, spintronics, quantum technology, and radiation sensors in harsh environments. ${ }^{1-3}$ However, despite the outstanding intrinsic materials properties of $\mathrm{ZnO}$, the doping asymmetry issue, where only n-type conductivity can be readily accomplished, limits the realization of homojunction bipolar $\mathrm{ZnO}$ devices. ${ }^{4,5}$

Nitrogen is perhaps one of the most promising candidates for p-type doping of $\mathrm{ZnO}$ and intensive studies of the effect of $\mathrm{N}$ on the $\mathrm{ZnO}$ conductivity have been undertaken during the past decade. ${ }^{6-11}$ However, the results obtained are quite contradictory. Among other doping techniques, ion implantation has been used to introduce $\mathrm{N}$ atoms in $\mathrm{ZnO}{ }^{6,7,12-14}$ Moreover, it has been demonstrated that a co-doping strategy where $\mathrm{N}$ is introduced together with other elements, such as $\mathrm{P}$ or $\mathrm{Zr}$, has a potential for realizing p-type $\mathrm{ZnO} .{ }^{15,16}$ In the case of ion implantation, ballistically generated primary defects as well as their thermal evolution have to be taken into account. Recently, it was shown by ion channeling measurements that the defect evolution in $\mathrm{N}$ implanted $\mathrm{ZnO}$ exhibits anomalous reverse annealing, that is, post-implant thermal treatment leads to an increase of the defect concentration instead of the crystal recovery typically observed for most other implanted elements in $\mathrm{ZnO}^{17}{ }^{17}$ This effect occurs exclusively for $\mathrm{N}$ ions and its mechanism is not yet well understood. It should be noted that $\mathrm{ZnO}$ belongs to the class of non-amorphizable materials and the origin of its high radiation resistance is still under debate. ${ }^{18-20}$ Generally, the defect formation/evolution in $\mathrm{ZnO}$ is complex and hinges strongly on the implanted species. ${ }^{17,21-23}$ For instance, it has been shown that dopant-defect reactions dominate the damage formation in B implanted samples resulting in an enhanced concentration of defect clusters as compared to other ion species. ${ }^{18}$ In contrast, for $\mathrm{Zn}$ or $\mathrm{Ag}$ ions, extended defects form readily already during implantation at room temperature (RT). ${ }^{21}$ In addition, comparison of random and channeled implants of $\mathrm{Ag}$ revealed that on-axis implantation reduces only the concentration of uncorrelated defect structures, while extended defects display a weak dependence on the crystal/beam alignment. ${ }^{24}$ In the present contribution, we utilize this effect to form a buried layer with a high density extended defects and study how these defects influence the thermal evolution of defects subsequently induced by $\mathrm{N}$ implantation at $\mathrm{RT}$ and $15 \mathrm{~K}$. A pronounced interplay between the different defects is found, and especially, the $\mathrm{N}$ implant temperature has a drastic influence on the reverse defect annealing occurring above $700^{\circ} \mathrm{C}$. Arguments are put forward for a model where a high local concentration of intrinsic point defects, like $\mathrm{Zn}$ interstitials, promotes the formation and stability of $\mathrm{N}$-defect clusters responsible for the reverse annealing effect.

\section{EXPERIMENTAL}

Samples were cut from hydrothermally (HT) grown wurtzite (0001) ZnO single crystals purchased from Mineral Ltd. The samples were divided into two sets and co-implanted or singly implanted with $\mathrm{Ag}$ and $\mathrm{N}$ ions, respectively. Initial RT implantation with $500 \mathrm{keV} \mathrm{Ag}^{+}$ions to a fluence of $5 \times 10^{15} \mathrm{~cm}^{-2}$ was performed for the first set of samples to 
TABLE I. Identification of the samples and implantation parameters used in the present study.

\begin{tabular}{|c|c|c|c|c|c|c|}
\hline & Sample & Ion & Energy (keV) & Fluence $\left(\mathrm{cm}^{-2}\right)$ & Tilt angle (deg) & Temperature \\
\hline \multirow[t]{4}{*}{ Set 1} & co-N(RT) & ${ }^{107} \mathrm{Ag}^{+}$ & 500 & $5 \times 10^{15}$ & 0 & RT \\
\hline & & ${ }^{14} \mathrm{~N}^{+}$ & 80 & $1 \times 10^{16}$ & 7 & RT \\
\hline & $\operatorname{co}-\mathrm{N}(15 \mathrm{~K})$ & ${ }^{107} \mathrm{Ag}^{+}$ & 500 & $5 \times 10^{15}$ & 0 & $\mathrm{RT}$ \\
\hline & & ${ }^{14} \mathrm{~N}^{+}$ & 80 & $1 \times 10^{16}$ & 7 & $15 \mathrm{~K}$ \\
\hline \multirow[t]{2}{*}{ Set 2} & Ag-ref & ${ }^{107} \mathrm{Ag}^{+}$ & 500 & $5 \times 10^{15}$ & 0 & RT \\
\hline & N-ref & ${ }^{14} \mathrm{~N}^{+}$ & 80 & $1 \times 10^{16}$ & 7 & RT \\
\hline
\end{tabular}

form a buried layer of extended defects. The beam of Ag ions was aligned along the [0001] direction. After the initial implantation, the samples were subjected to a second implantation at RT or $15 \mathrm{~K}$ with $80 \mathrm{keV} \mathrm{N}^{+}$ions to a fluence of $1 \times 10^{16} \mathrm{~cm}^{-2}$. The $\mathrm{N}$ implantations were carried out at $7^{\circ}$ off the normal direction in order to reduce channeling. The second set of samples was used for control and was singly implanted with $\mathrm{Ag}$ or $\mathrm{N}$ ions at RT using the same parameters as for the first set. In the following, the co-implanted samples are labeled as co- $\mathrm{N}(\mathrm{RT})$ and co- $\mathrm{N}(15 \mathrm{~K})$ for $\mathrm{N}$ implantations performed at RT and $15 \mathrm{~K}$, respectively, while the $\mathrm{N}$ and $\mathrm{Ag}$ control samples are labeled as N-ref and Ag-ref, respectively. The implantation parameters and identification of the samples are summarized in Table I. After the implantations, the samples were subjected to isochronal $(30 \mathrm{~min})$ anneals in the temperature range of $500-1100{ }^{\circ} \mathrm{C}$ in air ambient using a conventional tube furnace.

The structural quality of the implanted samples before and after the anneals was investigated by Rutherford backscattering spectrometry in channeling mode (RBS/C) with 1.6 $\mathrm{MeV}^{4} \mathrm{He}^{+}$ions incident along the [0001] direction and backscattered into a detector positioned at $165^{\circ}$ relative to the incident beam direction. Analysis of the acquired RBS/C spectra was performed using the DICADA code ${ }^{25}$ to deduce an effective number of scattering centers in the $\mathrm{Zn}$ sublattice, referred to below as "relative disorder." Selected samples were also analyzed by secondary ion mass spectrometry (SIMS) and the concentration versus depth profiles of $\mathrm{Ag}$ and $\mathrm{N}$ were measured using a Cameca IMS $7 \mathrm{f}$ microanalyzer with primary beams of $10 \mathrm{keV} \mathrm{O}_{2}{ }^{+}$and $15 \mathrm{keV} \mathrm{Cs}^{+}$ions for the analysis of $\mathrm{Ag}$ and $\mathrm{N}$, respectively. The intensityconcentration calibration was performed using as-implanted $\mathrm{ZnO}$ reference samples. Depth conversion of the recorded profiles was performed by measuring the sputtered crater depth using a Dektak 8 stylus profilometer and assuming a constant erosion rate.

\section{RESULTS AND DISCUSSION}

RBS/C spectra of a pre-damaged sample together with an unimplanted (virgin) one are shown in Fig. 1. The Ag implanted spectrum displays no well defined damage peak and is characterized by a high dechanneling yield in the lowenergy tail. As shown previously in the literature, a RBS/C spectrum of this shape indicates the presence of a high concentration of extended defects such as dislocation loops and/ or stacking faults. ${ }^{26,27}$ The depth distributions of implanted $\mathrm{N}$ atoms and $\mathrm{N}$-induced primary vacancies, as simulated by the SRIM code, ${ }^{28}$ are depicted in Fig. 1 relative to the $\mathrm{Zn}$ depth scale. The $\mathrm{N}$-induced defects are predominantly generated in the low damaged region between the sample surface and the pre-existing buried layer with maximum concentration of Ag-induced defects. The latter ones are primarily extended defects and known to affect the formation of $\mathrm{N}$ induced defects already during implantation. ${ }^{30}$ Thus, an influence during post-implant annealing may also be anticipated and Fig. 2 shows RBS/C spectra of (a) co-N(15 K) and (b) co$\mathrm{N}(\mathrm{RT})$ samples before and after annealing in the temperature range of $500-1100^{\circ} \mathrm{C}$, as indicated in the legends. For both samples, a substantial improvement of the crystal quality occurs only at temperatures above $1000^{\circ} \mathrm{C}$. However, the two sets of samples exhibit different behaviors in the temperature range of $650-900^{\circ} \mathrm{C}$. Indeed, in the co- $(15 \mathrm{~K})$ samples, the anneals at these temperatures affect mainly the $\mathrm{N}$-implanted region (100-200 nm), while in the co-(RT) samples annealing is observed also at large depths where the Ag-induced defects dominate [Fig. 2(b)].

In an attempt to elucidate the role of the implant temperature on the damage evolution in the co-implanted samples, disorder versus depth profiles were deduced using the DICADA code. ${ }^{25}$ DICADA calculations were performed under the assumption of randomly displaced lattice atoms not taking into account correlated defect structures. This assumption leads to a slight overestimation of the disorder fraction in the damaged region and also artificial deep tails

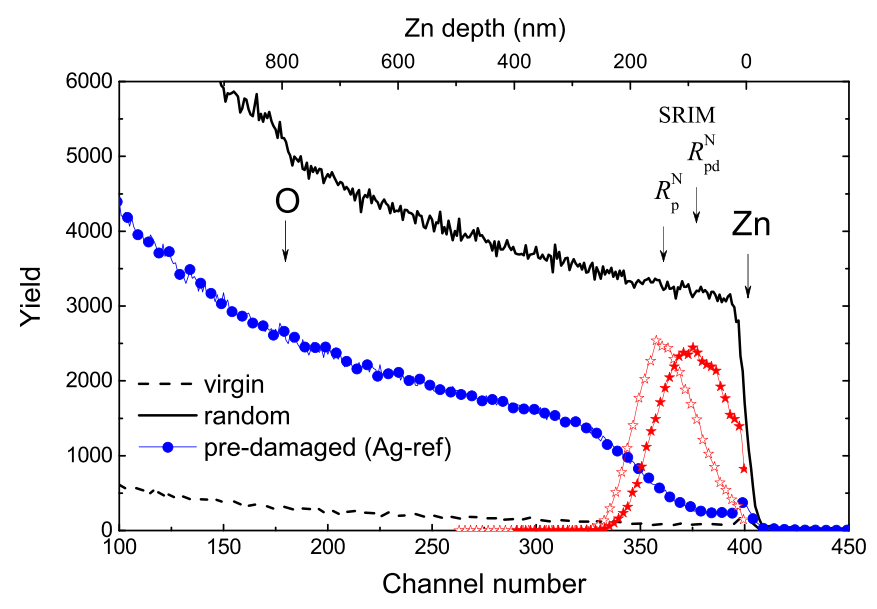

FIG. 1. RBS/C spectra of $\mathrm{ZnO}$ samples implanted with $500 \mathrm{keV} \mathrm{Ag}^{+}$ions to a fluence of $5 \times 10^{15} \mathrm{~cm}^{-2}$ in a channeling (0001) direction. The surface positions of $\mathrm{Zn}$ and $\mathrm{O}$ atoms are shown by the arrows. The channeling and random spectra of a virgin sample are also depicted for comparison (dashed and solid lines). The SRIM ${ }^{28}$ predicted profiles of lattice $\mathrm{Zn}$ and $\mathrm{O}$ vacancies (closed stars) and implanted $\mathrm{N}$ atoms (open stars) after bombardment with $80 \mathrm{keV} \mathrm{N}^{+}$ ions are displayed for comparison in correlation with the $\mathrm{Zn}$ depth scale. 


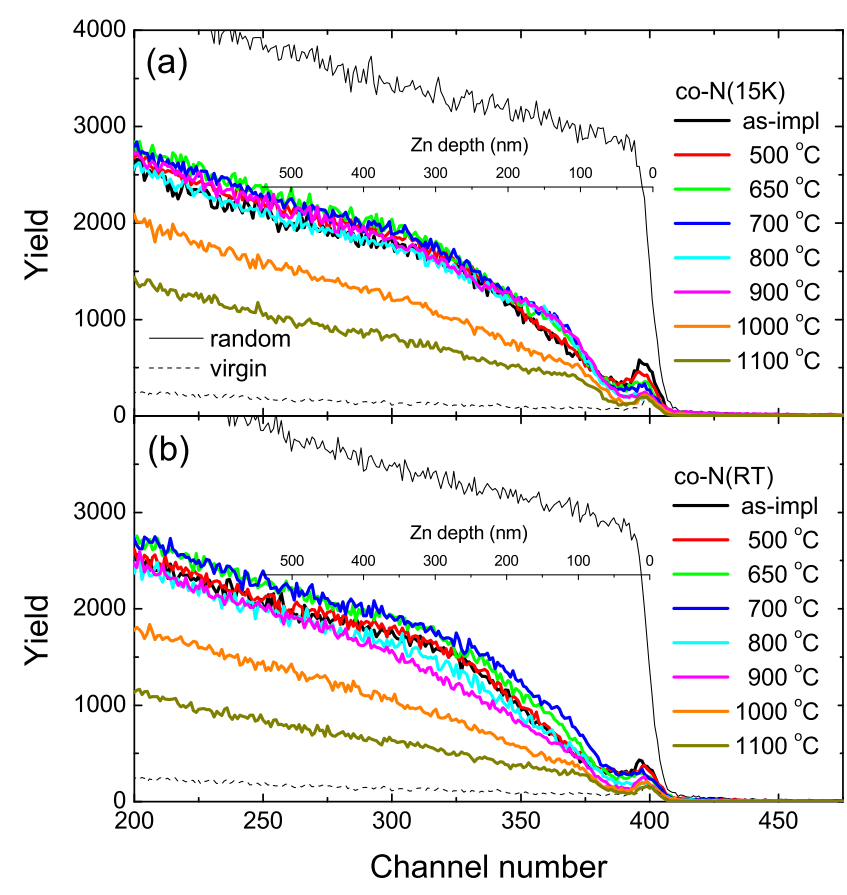

FIG. 2. RBS/C spectra of the (a) $15 \mathrm{~K}$ and (b) RT co-implanted $(\mathrm{Ag}+\mathrm{N})$ $\mathrm{ZnO}$ samples before and after annealing as indicated in the legends. The channeling and random spectra of a virgin sample are also depicted for comparison.

can occur if extended defects are present. ${ }^{26}$ Therefore, in contrast to the near surface damage, deep tails in damage depth profiles obtained from the DICADA code may arise from extended defects, rather than true deep disorder. Figure 3 shows the relative disorder versus depth profiles in the coimplanted and singly implanted samples before (a) and after isochronal anneals at temperatures between 650 and $1000^{\circ} \mathrm{C}$ (b)-(f). Prior to annealing, the $15 \mathrm{~K} \mathrm{~N}$ implantation produces slightly more defects as compared to that performed at RT [Fig. 3(a)]. However, annealing at $650{ }^{\circ} \mathrm{C}$ leads to some enhancement of the damage in all the $\mathrm{N}$-implanted samples, while it remains almost unchanged in the Ag control sample [Fig. 3(b)]. Increasing the temperature up to $700^{\circ} \mathrm{C}$ gives rise to a strong increase of the disorder in the $\mathrm{N}$ control sample and in both the $15 \mathrm{~K}$ and RT co-implanted samples, i.e., so-called reverse annealing takes place. It can be noted that the disorder starts to decrease in the Ag control sample at this temperature followed by a further and gradual crystal recovery at higher temperatures.

For the anneals at $800^{\circ} \mathrm{C}$ and above, a substantial effect of the $\mathrm{N}$ implantation temperature is revealed, Figs. 3(d)-3(f). After $800^{\circ} \mathrm{C}$, a strong reduction of the disorder occurs in the co-N(RT) sample at depths where the implanted $\mathrm{N}$ atoms are located $(\leq 0.25 \mu \mathrm{m})$. In contrast, the defect profile in the co-N $(15 \mathrm{~K})$ sample remains practically unchanged [see Fig. 3(d)]. This difference becomes even more pronounced after $900{ }^{\circ} \mathrm{C}$ where also the defects at even larger depths $(\leq 0.4 \mu \mathrm{m})$ start to disappear in the co-N(RT) sample [Fig. 3(e)]. Despite that the $1000^{\circ} \mathrm{C}$ anneal leads to a considerable defect removal in all the samples, a substantial part of the disorder still persists [Fig. 3(f)] and temperatures higher than $1000^{\circ} \mathrm{C}$ are needed for a complete recovery of the crystal structure.

The defect evolution in the co-implanted and singly implanted samples is summarized in Fig. 4(a) showing the relative disorder, taken in the region where the $\mathrm{N}$ concentration is maximal, as a function of the annealing temperature. Irrespective of pre-existing disorder or not, all the $\mathrm{N}$-implanted samples exhibit a strong reverse annealing at $700{ }^{\circ} \mathrm{C}$. However, the $\mathrm{N}$ implant temperature plays a dramatic role for the evolution at temperatures above $700{ }^{\circ} \mathrm{C}$. Indeed, in contrast to the N-ref and co-N(15 K) samples, displaying similar trends with a distinct reverse annealing stage at $700{ }^{\circ} \mathrm{C}$ followed by almost no change up to $900^{\circ} \mathrm{C}$, the co$\mathrm{N}(\mathrm{RT})$ sample reveals gradual and substantial loss of disorder at and above $800{ }^{\circ} \mathrm{C}$.

In order to further elucidate the observed behavior, we have subtracted the disorder depth profile deduced for the Nref sample from those of the co-implanted ones. These profiles
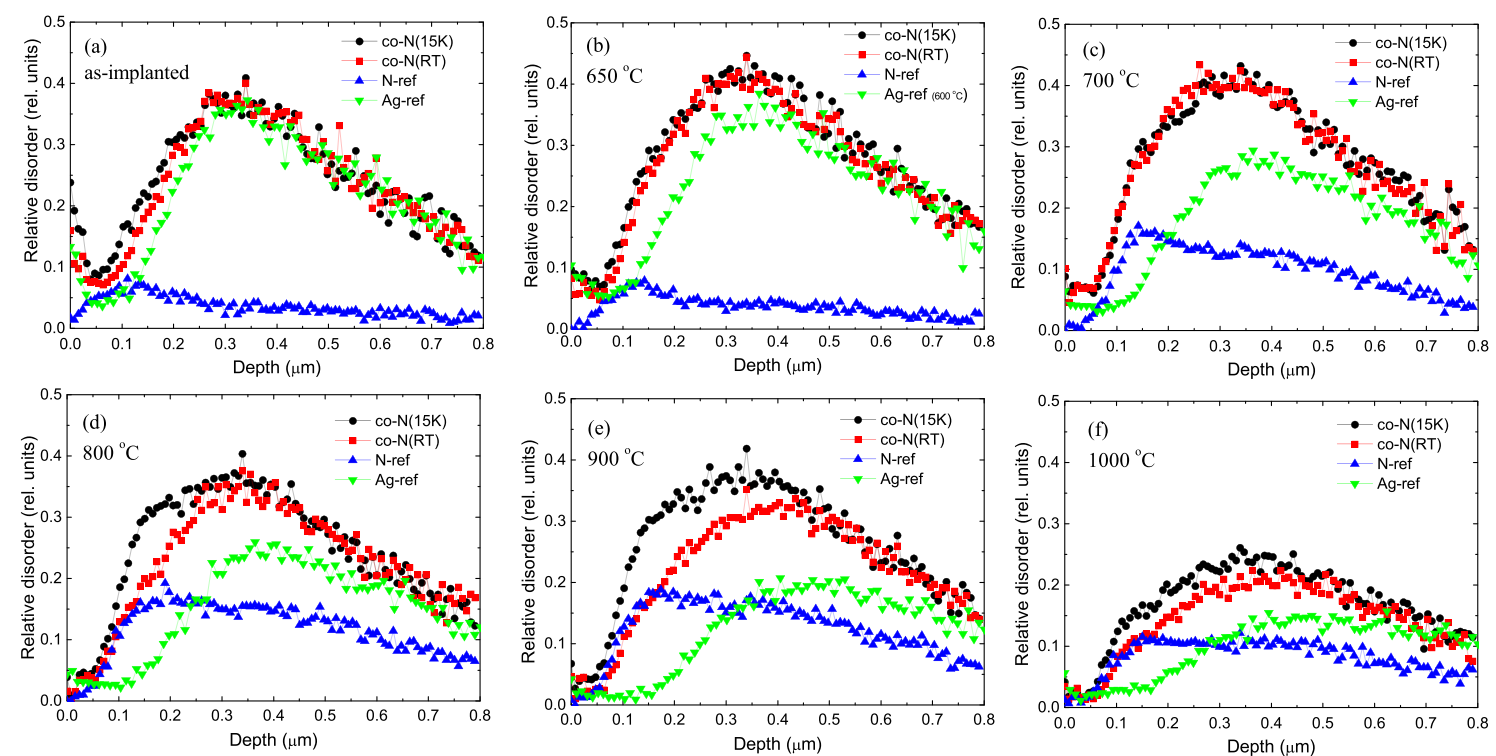

FIG. 3. Depth profiles of the relative disorder in the $15 \mathrm{~K}$ and $\mathrm{RT}$ co-implanted $(\mathrm{Ag}+\mathrm{N}) \mathrm{ZnO}$ samples before and after annealing as indicated in the legends. The depth profiles of the relative disorder in the reference samples are shown for comparison at each annealing temperature. 

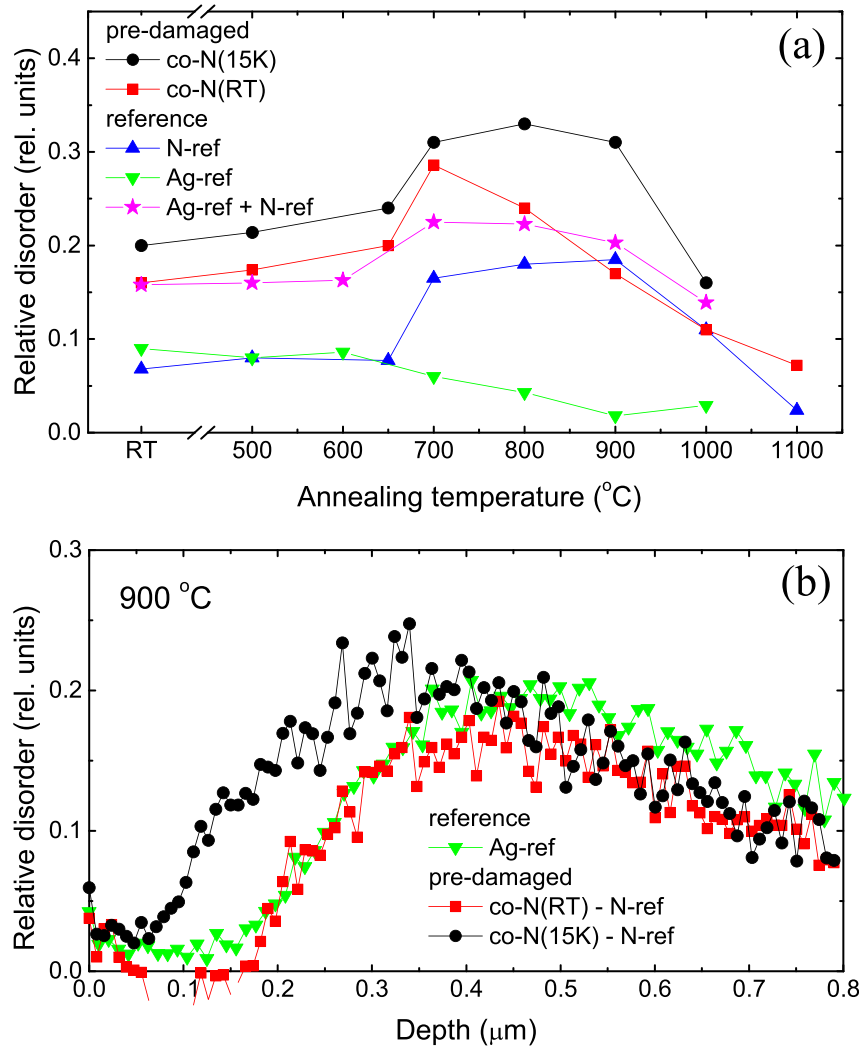

FIG. 4. (a) Relative disorder in the region where the concentration of implanted $\mathrm{N}$ atoms is maximal, as a function of annealing temperature. The sum of the data for the $\mathrm{N}$ and Ag control samples is shown by the stars. (b) Depth profiles of the relative disorder on the $\mathrm{Zn}$ sublattice after $900{ }^{\circ} \mathrm{C}$ annealing in the co-implanted samples after subtraction of the disorder for the $\mathrm{N}$ control sample (the depth profile of the relative disorder in the Ag control sample is shown for comparison).

are depicted in Fig. 4(b) for the $900{ }^{\circ} \mathrm{C}$ anneal where also the profile for the Ag-ref sample is included for comparison. The subtracted profile for the co-N(RT) sample resembles closely the one for the Ag-ref sample, indicating that the evolutions of $\mathrm{Ag}$ - and $\mathrm{N}$-induced defects in the co-N(RT) samples occur almost independently. The same conclusion holds also for the as-implanted samples displaying additive accumulation of disorder, i.e., the damage in the co-N(RT) sample equals the sum of that in the N-ref and Ag-ref samples as illustrated by the stars in Fig. 4(a). However, after annealing in the range of $500-800{ }^{\circ} \mathrm{C}$, the co-implanted samples exhibit more disorder as compared to the sum of that in the two control samples. Thus, a pronounced interaction between the $\mathrm{N}$ - and Ag-induced defects is evident at moderate post-implant temperatures.

It should be underlined that the initial Ag implantation can induce a substantial concentration of extended defects also in the near surface region, despite a relatively low disorder level deduced from RBS/C spectra. Indeed, it has previously been shown that aligned Ag implantation causes a large amount of basal plane stacking faults (BPSF). ${ }^{24}$ These defects give only a minor contribution to the direct backscattering yield of the analyzing $\mathrm{He}^{+}$ions and are, therefore, not clearly distinguishable by standard channeling techniques. ${ }^{20}$ It appears likely that the $\mathrm{N}$-induced defects interact with these extended defects during annealing, enhancing the backscattering yield. Here, it should be emphasized that the exact mechanisms of the observed reverse annealing are not known (as mentioned above), except that the presence of $\mathrm{N}$ is a necessary condition. ${ }^{17}$ Literature data on defect microstructures in $\mathrm{N}$ implanted $\mathrm{ZnO}$ samples are limited and somewhat contradictory. Perillat-Merceroz et al. ${ }^{13}$ reported two distinct regions of enhanced density of BPSF located near the surface and one of prismatic loops in the end-ofrange region. According to the simulations by Turos et al., ${ }^{20}$ BPSF lead to strain accumulation which may act as a driving force for defect migration and agglomeration of extended defects. In its turn, prismatic loops enhance dechanneling during RBS/C analysis and, therefore, increase backscattering yield beyond the implanted region. Annealing studies revealed that prismatic loops are less thermally stable as compared to BPSF and disappear already at $900{ }^{\circ} \mathrm{C}$ together with a complete strain relaxation. ${ }^{13}$ In contrast to Ref. 13 , Myers et al. ${ }^{6}$ reported an enhanced concentration of defect clusters for implants performed at $300{ }^{\circ} \mathrm{C}$, while $\mathrm{N}$ implantation at $460{ }^{\circ} \mathrm{C}$ leads to the formation of extended defects and BPSF dominate. Further, our results show an increase of the concentration of extended defects causing dechanneling after anneals at $700-900{ }^{\circ} \mathrm{C}$ and a large fraction of these defects still persists after $900^{\circ} \mathrm{C}$ where prismatic loops are expected to have disappeared. ${ }^{13}$ However, in the present work, we use higher $\mathrm{N}$ fluence as compared to those in Refs. 6 and 13, and it is evident that more microstructural investigations are required for a better understanding of the anomalous defect annealing behavior in $\mathrm{N}$ implanted $\mathrm{ZnO}$ samples. Here, it should also be noted that the $\mathrm{N}$ fluences used in the present study are not high enough to cause formation of $\mathrm{N}$ gas bubbles, as expected for extremely high $\mathrm{N}$ concentrations. ${ }^{29}$

In any case, the following defect interaction scenario and conclusions can be put forward for the co-implanted samples. First, prior to annealing, the co-N(15 K) samples display more disorder as compared to the co-N(RT) ones [see Fig. 4(a)]. This is consistent with the previously reported results in Ref. 30 and is attributed to partial suppression of dynamic annealing at cryogenic temperatures together with limited migration of point defects from the $\mathrm{N}$-implanted volume to the buried layer of extended defects. The latter is known to act as annihilation/trapping sites for point defects. ${ }^{30}$ Second, in contrast to the co-N(RT) samples, the co-N(15 K) and the N-ref samples exhibit a similar trend of disorder over the entire annealing temperature range studied [see Fig. 4(a)]; the two curves are parallel and only displaced by the additional amount of disorder arising from the $15 \mathrm{~K} \mathrm{~N}$ implant in combination with the pre-existing defects. Hence, by a comparison of the $800^{\circ} \mathrm{C}$ and $900^{\circ} \mathrm{C}$ data in Fig. 4(a) for the co-N(RT) and co-N(15 K) samples and the $\mathrm{N}$-ref sample, it appears evident that the point defects "escaping" to the buried layer of extended defects in the former sample during implantation have a decisive impact on the reverse annealing process. These point defects are presumable $\mathrm{Zn}$ interstitials $\left(\mathrm{Zn}_{\mathrm{i}}\right)$, being mobile already at RT. ${ }^{31,32}$ The disorder emerging at the $\mathrm{Zn}$ sublattice in the co$\mathrm{N}(\mathrm{RT})$ sample during the reverse annealing stage displays low thermal stability relative to that in the two other samples, suggesting that a high local concentration of $\mathrm{Zn}_{\mathrm{i}}$ 's promotes the stability of the emerging defects. Accordingly, it can be 


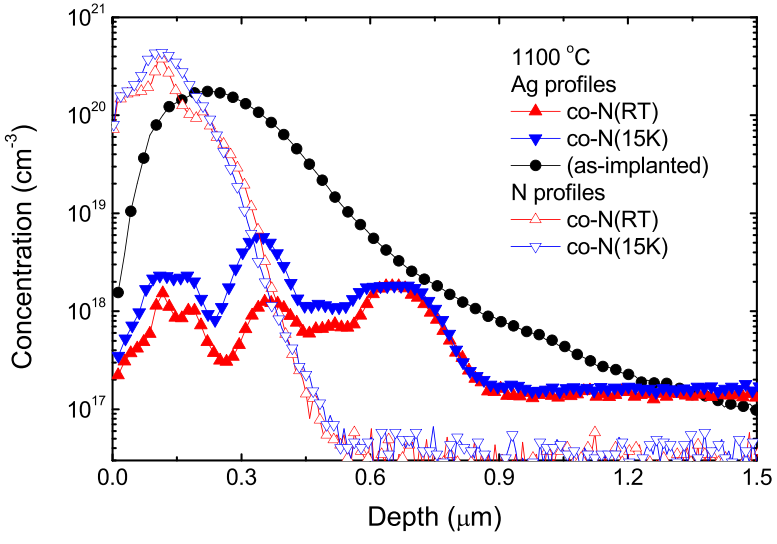

FIG. 5. Ag and $\mathrm{N}$ concentration vs. depth profiles as measured by SIMS in the $15 \mathrm{~K}$ and RT co-implanted samples. The profiles illustrate a drastic $\mathrm{Ag}$ redistribution in the vicinity of the implanted peak after annealing at $1100^{\circ} \mathrm{C}$. The $\mathrm{Ag}$ as-implanted depth profile is shown for the comparison (filled circles).

speculated that formation of clusters involving $\mathrm{N}$ and $\mathrm{Zn}_{\mathrm{i}}$ 's is responsible for the observed reverse annealing, where a sufficiently large cluster size enhances their thermal stability.

This speculation is further supported by Fig. 5 showing concentration versus depth profiles of $\mathrm{N}$ and $\mathrm{Ag}$ in co-N(RT) and co-N $(15 \mathrm{~K})$ samples after annealing at $1100^{\circ} \mathrm{C}$. Drastic drastic redistribution and diffusion of the $\mathrm{Ag}$ atoms are found, while the $\mathrm{N}$ atoms exhibit only a minor effect. The Ag profiles display three distinct peaks and a pronounced diffusion shoulder at the level of $\sim 2 \times 10^{17} \mathrm{~cm}^{-3}$ for depths $\geq 1 \mu \mathrm{m}$ in both the samples. This Ag behavior is consistent with previously published results ${ }^{33}$ where the Ag migration into the crystal bulk was attributed to trap-limited diffusion and zinc vacancies as likely trapping sites. In its turn, the two anomalous peaks, located shallower and deeper than the central main one, were attributed to trapping of $\mathrm{Ag}$ atoms at open volume defects formed due to local ion-induced stoichiometry perturbations. ${ }^{33,34}$ That is, the near surface $(\sim 150 \mathrm{~nm})$ and end-ofrange $(\sim 700 \mathrm{~nm})$ peaks are presumably caused by Ag trapping at oxygen and zinc vacancies, respectively. A quantitative comparison of the $\mathrm{Ag}$ concentration profiles in the present co-N(RT) and co-N(15 K) samples with those in singly Ag implanted samples (Fig. 4 in Ref. 33) reveals a considerably enhanced outdiffusion in the co-implanted samples after $1100^{\circ} \mathrm{C}$ anneal. This holds especially for the co-N(RT) sample where the near-surface and central Ag peaks are substantially reduced relative to those in the co-N(15 K) sample. This indicates a high release of point defects (e.g., Zn interstitials) in the co-N(RT) sample mediating the Ag outdiffusion and it also complies with a less stable reverse annealing effect because of the lower thermal stability of the responsible $\mathrm{N}$ defect clusters.

\section{CONCLUSIONS}

In summary, we have studied the defect evolution in $\mathrm{ZnO}$ samples singly implanted with $\mathrm{Ag}$ or $\mathrm{N}$ ions or co-implanted $(\mathrm{Ag}+\mathrm{N})$ where the $\mathrm{N}$ implants were performed at RT or $15 \mathrm{~K}$ subsequent to channeled implants by the Ag ions. RBS/C analysis shows that irrespective of a buried pre-existing defect layer or not, all the $\mathrm{N}$ implanted samples exhibit strong reverse annealing with non-additive effects of damage enhancement in the co-implanted samples. Further, the processes of dynamic annealing and point defect migration during implantation play a central role for the $\mathrm{N}$-induced defect evolution at post-implant annealing above $700{ }^{\circ} \mathrm{C}$. Especially, a deficit of point defects (presumably $\mathrm{Zn}_{\mathrm{i}}$ 's) in the N-doped volume, due to out-diffusion at RT and trapping/annihilation by the buried Ag-induced extended defects, give rise to a low thermal stability of the $\mathrm{N}-\mathrm{Zn}$ associated defects emerging during the reverse annealing stage.

\section{ACKNOWLEDGMENTS}

This work was performed within the Research Centre for Sustainable Solar Cell Technology (FME SuSolTech, Project No. 257639), co-sponsored by the Norwegian Research Council and research and industry partners. Financial support was also kindly provided by the Research Council of Norway and University of Oslo through the frontier research project FUNDAMeNT (No. 251131, FriPro ToppForsk-program).

${ }^{1}$ Ü. Özgür, Y. I. Alivov, C. Liu, A. Teke, M. A. Reshchikov, S. Doğan, V. Avrutin, S.-J. Cho, and H. Morkoç, "A comprehensive review of $\mathrm{ZnO}$ materials and devices," J. Appl. Phys. 98, 041301 (2005).

${ }^{2}$ A. B. Djurišić, A. M. C. Ng, and X. Y. Chen, "ZnO nanostructures for optoelectronics: Material properties and device applications," Prog. Quantum Electron. 34, 191 (2010).

${ }^{3} \mathrm{C}$. Liu, F. Yun, and H. Morkoç, "Ferromagnetism of $\mathrm{ZnO}$ and $\mathrm{GaN}$ : A review,” J. Mater. Sci.: Mater. Electron. 16, 555 (2005).

${ }^{4}$ C. H. Park, S. B. Zhang, and S.-H. Wei, "Origin of p-type doping difficulty in ZnO: The impurity perspective," Phys. Rev. B 66, 073202 (2002).

${ }^{5}$ V. Avrutin, D. J. Silversmith, and H. Morkoç, "Doping asymmetry problem in ZnO: Current status and outlook," Proc. IEEE 98, 1269 (2010).

${ }^{6}$ M. A. Myers, M. T. Myers, M. J. General, J. H. Lee, L. Shao, and H. Wang, "P-type $\mathrm{ZnO}$ thin films achieved by $\mathrm{N}^{+}$ion implantation through dynamic annealing process," Appl. Phys. Lett. 101, 112101 (2012).

${ }^{7}$ J. Kennedy, D. A. Carder, A. Markwitz, and R. J. Reeves, "Properties of nitrogen implanted and electron beam annealed bulk ZnO," J. Appl. Phys. 107, 103518 (2010).

${ }^{8}$ T. M. Barnes, K. Olson, and C. A. Wolden, "On the formation and stability of p-type conductivity in nitrogen-doped zinc oxide,” Appl. Phys. Lett. 86, 112112 (2005).

${ }^{9}$ J. G. Reynolds, C. L. Reynolds, Jr., A. Mohanta, J. F. Muth, J. E. Rowe, H. O. Everitt, and D. E. Aspnes, "Shallow acceptor complexes in p-type ZnO,” Appl. Phys. Lett. 102, 152114 (2013).

${ }^{10}$ M. Ding, D. Zhao, B. Yao, B. Li, Z. Zhang, and D. Shen, "The p-type ZnO film realized by a hydrothermal treatment method," Appl. Phys. Lett. 98, 062102 (2011).

${ }^{11}$ S. Lautenschlaeger, S. Eisermann, G. Haas, E. A. Zolnowski, M. N. Hofmann, A. Laufer, M. Pinnisch, B. K. Meyer, M. R. Wagner, J. S. Reparaz, G. Callsen, A. Hoffmann, A. Chernikov, S. Chatterjee, V. Bornwasser, and M. Koch, "Optical signatures of nitrogen acceptors in ZnO,” Phys. Rev. B 85, 235204 (2012).

${ }^{12}$ M. Schmidt, M. Ellguth, F. Schmidt, T. Lüder, H. v. Wenckstern, R. Pickenhain, M. Grundmann, G. Brauer, and W. Skorupa, "Defects in a nitrogen-implanted ZnO thin film," Phys. Status Solidi B 247, 1220 (2010).

${ }^{13}$ G. Perillat-Merceroz, P. Gergaud, P. Marotel, S. Brochen, P.-H. Jouneau, and G. Feuillet, "Formation and annealing of dislocation loops induced by nitrogen implantation of ZnO,” J. Appl. Phys. 109, 023513 (2011).

${ }^{14}$ J. Kennedy, P. P. Murmu, E. Manikandan, and S. Y. Lee, "Investigation of structural and photoluminescence properties of gas and metal ions doped zinc oxide single crystals," J. Alloys Compd. 616, 614 (2014). 
${ }^{15}$ X.-Y. Duan, Y.-J. Zhao, and R.-H. Yao, "Pushing p-type conductivity in $\mathrm{ZnO}$ by $(\mathrm{Zr}, \mathrm{N})$ codoping: A first-principles study," Solid State Commun. 147, 194 (2008)

${ }^{16}$ Y. Sui, B. Yao, L. Xiao, G. Xing, L. Yang, X. Li, X. Li, J. Lang, S. Lv, J. Cao, M. Gao, and J. Yang, "Effects of (P, N) dual acceptor doping on band gap and p-type conduction behavior of $\mathrm{ZnO}$ films," J. Appl. Phys. 113, 133101 (2013).

${ }^{17}$ A. Azarov, A. Galeckas, E. Wendler, J. Ellingsen, E. Monakhov, and B. G. Svensson, "Normal and reverse defect annealing in ion implanted II-VI oxide semiconductors," J. Appl. Phys. 122, 115701 (2017).

${ }^{18}$ A. Yu. Azarov, E. Wendler, A. Yu. Kuznetsov, and B. G. Svensson, "Crucial role of implanted atoms on dynamic defect annealing in $\mathrm{ZnO}$," Appl. Phys. Lett. 104, 052101 (2014).

${ }^{19}$ K. Trachenko, J. M. Pruneda, E. Artacho, and M. T. Dove, "How the nature of the chemical bond governs resistance to amorphization by radiation damage," Phys. Rev. B 71, 184104 (2005).

${ }^{20}$ A. Turos, P. Jóźwik, M. Wójcik, J. Gaca, R. Ratajczak, and A. Stonert, "Mechanism of damage buildup in ion bombarded $\mathrm{ZnO}$," Acta Mater. 134, 249 (2017).

${ }^{21}$ A. Yu. Azarov, A. Hallén, X. L. Du, P. Rauwel, A. Yu. Kuznetsov, and B. G. Svensson, "Effect of implanted species on thermal evolution of ioninduced defects in ZnO, J J. Appl. Phys. 115, 073512 (2014).

${ }^{22}$ E. Sonder, R. A. Zhur, and R. E. Valiga, "Annealing of damage and stability of implanted ions in ZnO crystals," J. Appl. Phys. 64, 1140 (1988).

${ }^{23}$ Z. Q. Chen, M. Maekawa, A. Kawasuso, R. Suzuki, and T. Ohdaira, "Interaction of nitrogen with vacancy defects in $\mathrm{N}^{+}$-implanted $\mathrm{ZnO}$ studied using a slow positron beam,” Appl. Phys. Lett. 87, 091910 (2005).

${ }^{24}$ A. Azarov, P. Rauwel, A. Hallén, E. Monakhov, and B. G. Svensson, "Extended defects in ZnO: Efficient sinks for point defects," Appl. Phys. Lett. 110, 022103 (2017).
${ }^{25} \mathrm{~K}$. Gärtner, "Modified master equation approach of axial dechanneling in perfect compound crystals," Nucl. Instrum. Methods Phys. Res., Sect. B 227, 522 (2005).

${ }^{26}$ E. Wendler, O. Bilani, K. Gärtner, W. Wesch, M. Hayes, F. D. Auret, K. Lorenz, and E. Alves, "Radiation damage in $\mathrm{ZnO}$ ion implanted at $15 \mathrm{~K}$," Nucl. Instrum. Methods Phys. Res., Sect. B 267, 2708 (2009).

${ }^{27}$ A. Turos, L. Nowicki, A. Stonert, K. Pagowska, J. Jagielski, and A. Muecklich, "Monte Carlo simulations of ion channeling in crystals containing extended defects," Nucl. Instrum. Methods Phys. Res., Sect. B 268, 1718 (2010).

${ }^{28}$ J. F. Ziegler, J. P. Biersack, and U. Littmark, The Stopping and Range of Ions in Solids (Pergamon, New York, 1985), Vol. 1, p. 109.

${ }^{29}$ C. Silva, A. R. G. Costa, M. M. Cruz, R. C. da Silva, R. P. Borges, L. C. Alves, and M. Godinho, "Nitrogen and argon doped zinc oxide," J. Phys.: Condens. Matter 22, 346005 (2010).

${ }^{30}$ A. Azarov, E. Wendler, K. Lorenz, E. Monakhov, and B. G. Svensson, "Effect of buried extended defects on the radiation tolerance of $\mathrm{ZnO}$," Appl. Phys. Lett. 110, 172103 (2017).

${ }^{31}$ C. Bhoodoo, A. Hupfer, L. Vines, E. V. Monakhov, and B. G. Svensson, "Evolution kinetics of elementary point defects in $\mathrm{ZnO}$ implanted with low fluences of helium at cryogenic temperature," Phys. Rev. B 94, 205204 (2016).

${ }^{32}$ A. Janotti and C. G. Van de Walle, "Native point defects in ZnO," Phys. Rev. B 76, 165202 (2007).

${ }^{33}$ A. Azarov, L. Vines, P. Rauwel, E. Monakhov, and B. G. Svensson, "Silver migration and trapping in ion implanted $\mathrm{ZnO}$ single crystals," J. Appl. Phys. 119, 185705 (2016)

${ }^{34}$ L. A. Christel and J. F. Gibbons, "Stoichiometric disturbances in ion implanted compound semiconductors," J. Appl. Phys. 52, 5050 (1981). 